\title{
John Hunter y el gonococo
}

\author{
WALTER LEDERMANN D.
}

\section{John Hunter and the Gonococcus}

Cualquiera historia tentativa del popular gonococo, estará inevitablemente ligada a los nombres de John Hunter (1728-1793), Philippe Ricord (1800-1889) y Albert Neisser (1855-1916), quienes intervinieron decisivamente - bien o mal- en el devenir de las investigaciones sobre la gonorrea. Esta enfermedad, conocida desde la antigüedad, recibió erróneamente el nombre que habría de perdurar, pues su traducción literal es "flujo seminal" (gono rhein), estimándose que lo que hoy conocemos como pus era espermatorrea, debida a una putrefacción del semen. Otro de sus múltiples nombres era blenorragia, literalmente flujo mucoso . Cuando la sífilis apareció en Europa, la blenorragia era ampliamente conocida. La encontramos en la Biblia, donde se indican ciertos procedimientos profilácticos contra ella. Incluso Moisés dictó leyes contra el flujo seminal, según las cuales el enfermo era considerado impuro no sólo durante la enfermedad, sino hasta siete días después de cesado el flujo. La consideran igualmente textos chinos de hace 5.000 años. En los antiguos escritos indios de Susruta, se describe una patología que concuerda con la gonorrea, y también figura en los de los médicos griegos y latinos: Hipócrates la llamó stranguria en el 460 a.C., Galeno ya utilizó el término actual de gonorrea en el 200 d.C., en tanto que Celso habló del flujo seminal. En los tratados de médicos árabes se indica que esta afección se contrae por coitus cum immundis, es decir, por contacto sexual con un "inmundo". En la Edad Media se la conoció por una infinidad de nombres pintorescos: mictus saniei, ulceratio interna, seminis lapsus, fluxus, profluvium pudenda, fluxura geniturae, rheumatisatio virgae, calefactio in virga, incendium, arsura virgae, urethralgia, ardor urinae, leucorrhoea, medorrhoea, phalorrhoea y, por último y en un ingenioso juego de palabras, asociándola a la perdición imperante en Gomorra, como gomorrhoea. Era entonces un síndrome y no una enfermedad, ya que obedecía a múltiples causas, cobijando bajo un mismo nombre a patologías disímiles, como ha ocurrido con casi todas las enfermedades en épocas pasadas.

La confusión comenzó con la aparición en Europa de la epidemia de sífilis en 1494, que se supuso importada desde las Indias (hoy América). Se estableció una distinción entre dos formas clínicas, la gallica o francígena y la non gallica, "aceptándose por lo tanto, la idea que la sífilis podía presentarse a consecuencia de la blenorragia, de la misma manera que a consecuencia del chancro, teoría identista que dominó durante dos siglos".
En la época de Hunter, el siglo XVIII, la confusión persistía y el error más corriente era considerar que sífilis y gonorrea constituían expresiones clínicas de una misma enfermedad, en tanto que una ínfima y selecta minoría postulaba la teoría contraria (teoría dualista). La confusión es fácil de entender, pues en esa época pre-pasteurina, en que no podía hacerse (ni imaginarse) un aislamiento bacteriano, la simple observación demostraba que quienes tenían gonorrea... terminaban teniendo lúes, cosa que hoy nos resulta muy comprensible, dado que ambos microbios seguían la misma vía de contagio sexual en personas "de alto riesgo". Por desgracia, en el año 1767, cuando Balfour había demostrado claramente en Edimburgo la inexistencia de la blenorragia sifilítica, esto es, que la sífilis no era la secuencia obligada de la gonorrea, tesis apoyada por investigadores tan distinguidos como Morgangi, Ellis y Tode, aparece John Hunter, quien queriendo probar la teoría dualista, terminaría por reafirmar a los unicistas.

La historia de este célebre cirujano y anatomista inglés es más conocida por su lado pintoresco que por el científico, aunque fue uno de los padres de la cirugía moderna. Sabemos que desde pequeño coleccionó y destripó insectos y sapos, que su hermano William, diez años mayor, famoso y pulido cirujano de Londres, mandó llamar como asistente a este John, diestro en la disección, burdo e inhábil en la presentación y en el lenguaje, pero tan tesonero y entusiasta como para llegar a alturas que el otro jamás imaginara. Johm Hunter nació en Escocia en 1728 y era el hijo menor de una larga familia. Mal alumno, se interesó poco en los estudios, excepto en los relacionados con la historia natural. Tenía 20 años cuando William lo llamó a Londres, donde había fundado una escuela para dar lecciones de anatomía a los cirujanos británicos. Tales escuelas adquirieron categoría legal en Inglaterra en 1745, al disolverse la Compañía de Barberos Cirujanos, comenzando con su fundación una era de investigaciones en el cuerpo humano. La leyenda presenta a John Hunter descuartizando, en la tranquilidad de su hogar, a grandes mamíferos, cuyos miembros hervía en un enorme caldero de cobre empotrado en la pared de una bodega (que a su muerte sería subastado en 36 chelines), para así separar los huesos de la carne, olvidando el aporte que estas investigaciones, no por desordenadas menos valiosas, hicieron a la anatomía comparada, sin olvidar lo que añadieron a la destreza natural del investigador. Los preceptos que John Hunter estableció en cirugía eran 
“muy estimulantes y se leían mucho", pero su propia consulta privada era exigua y sus dificultades económicas muchas. En 1794, un año después de su muerte, apareció su libro Treatise on the blood, inflammation and gun-shot wounds. Aquí encontramos la explicación de que tuvieran tanto éxito las conferencias de Hunter, que con frecuencia combinaban cirugía, fisiología y patología. Hunter consideraba que "en ocasiones la inflamación no sólo resulta causa de enfermedad, sino que muchas veces es un modo de curación". Por lo tanto, la inflamación pasó a ser el "primer principio de la cirugía". Fue igualmente conocido su estudio sobre la ligadura de los vasos arteriales en casos de aneurisma, basados en supuestas observaciones experimentales en astas de ciervo, permitiéndole percatarse que la circulación colateral bastaría si se ligaba el vaso por encima del aneurisma, evitando la amputación cuando estaban afectadas la femoral o la poplítea. Esto representó una gran ventaja en terapéutica quirúrgica y fue el verdadero comienzo de la cirugía conservadora, que sería trascendente en el siglo XIX. En palabras del historiador Fielding Garrison, "con la aparición de John Hunter, la cirugía dejó de considerarse una simple técnica terapéutica y empezó a ocupar un lugar como rama de la medicina científica, fundada primeramente en la fisiología y la patología". Sus mejores logros científicos comprenden la descripción de las ramificaciones de los nervios nasales y olfatorio, la comprensión del descenso de los testículos en el feto y la demostración de la función e importancia del sistema linfático en animales, junto a algunos estudios de coagulación y otros de conducta animal.

Bien, pero... ¿qué tuvo que ver John Hunter con el gonococo? Hombre de múltiples inquietudes, el campo de las enfermedades infecciosas no el pareció incompatible con el de la cirugía y, entre otras cosas, quiso demostrar en definitiva su teoría del contagio de la gonorrea a través del pus, terminando, según el historiador W. Bulloch, por "inocularse a si mismo en el pene con una lanceta sumergida en materia de un caso de gonorrea (Mayo, 1767)". La cita es textual; otros autores soslayan el hecho y hablan de inoculación accidental. Si fue voluntaria, habla de una curiosidad científica incontenible y de un coraje a toda prueba, ambas características muy propias de Hunter. El hecho es que, además de la blenorragia, presentó toda la sintomatología de la sífilis, pues sin duda el enfermo era portador de ambas enfermedades de trasmisión sexual, hecho frecuente entonces y ahora. La conclusión del arriesgado investigador fue que ambos cuadros eran dos manifestaciones, sucesivas en el tiempo, de una misma enfermedad. Este experimento derivó en una ver- dadera tragedia, de pormenores embarazosos, ya que John se había enamorado de la pulcra y distinguida señorita Anne Home y esperaba casarse pronto. El treponema dijo otra cosa y el matrimonio hubo de posponerse por tres largos años, durante los cuales el afectado se trató con mercurio, hizo interesantes observaciones sobre la sífilis y describió el chancro de inoculación o chancro de Hunter. Aparentemente curó de la sífilis o, al menos y milagrosamente, no infectó a su señora, con la que tuvo buena descendencia, viviendo en una casa curiosísima, que albergaba a la vez un museo de historia natural y un zoológico, y que se dice habría servido de modelo a Robert Louis Stevenson para la casa del Dr. Jekyll.

La autoinoculación de Hunter, probó inequívocamente que gonorrea y sífilis era una misma enfermedad con dos fases clínicas, dando el espaldarazo triunfal a la teoría unicista. Siete años después de su funeral, nacería el hombre que iba a demostrar que la inequívoca prueba era errónea: Philippe Ricord (17991899).

El nombre de Ricord permanece en el lenguaje médico sólo ligado al chancro sifilítico inicial, en forma de parche. Conocido como chancro de Ricord; también creo que hay una sonda de Ricord. Sin embargo, fue un hombre de excepcional talento, cuyos aportes a la ginecología distan de ser despreciables. En el campo de las enfermedades infecciosas logró establecer definitivamente en 1831, mediante centenares de inoculaciones y siguiendo los trabajos iniciados por Benjamin Bell, Astley Cooper y otros, que la sífilis y la gonorrea eran enfermedades distintas, así como diferenciar el chancro duro luético del chancro blando. Para Ricord, empero, si bien la sífilis era una enfermedad, la blenorragia o gonorrea era un síndrome, ya que pensaba obedecería a distintas etiologías. Faltaba Neisser para terminar de aclarar las cosas.

\section{Bibliografía}

1.- Brieger Gert. Desarrollo de la cirugía. En David C Sabiston, Tratado de Patología Quirúrgica de David Christopher, 10th Ed., Ed.Interamericana, México 1974; pp. 7-8.

2.- Young A. Escalpelo. Ed. Garriga S.A., Madrid 1957; pp. 85-112.

3.- Eulenburg A. Diccionario enciclopédico de medicina y cirugía. A. Jubera Editor, Madrid 1886; II: 83-84.

4.- Carpenter, C.M. Venereal diseases. In: Halsey, W.D. Collier's Encyclopedia, Crowell Collier and MacMillan, Inc., Phi 1967; vol 23: 61-2.

5.- Bulloch W. History. In: Medical Research Council. A system of bacteriology in relation to medicine. His Majesty's Stationery Office, London, 1929; II: 23941. 